\title{
Brazilian Red-Eyed Fly Ormia depleta (Wiedemann) (Diptera: Tachinidae) ${ }^{1}$
}

\author{
Haleigh Ray and Jennifer L. Gillett-Kaufman²
}

\section{Introduction}

The Brazilian red-eyed fly, Ormia depleta (Wiedemann) (Figure 1), is a tachinid fly that is a parasitoid of mole crickets in the genus Neoscapteriscus (Orthoptera: Gryllotalpidae). Originally from South America, it was brought to the United States for biological control of pest mole crickets. It is now established in almost all counties in central and southern Florida (Frank et al. 1996; Walker et al. 1996).

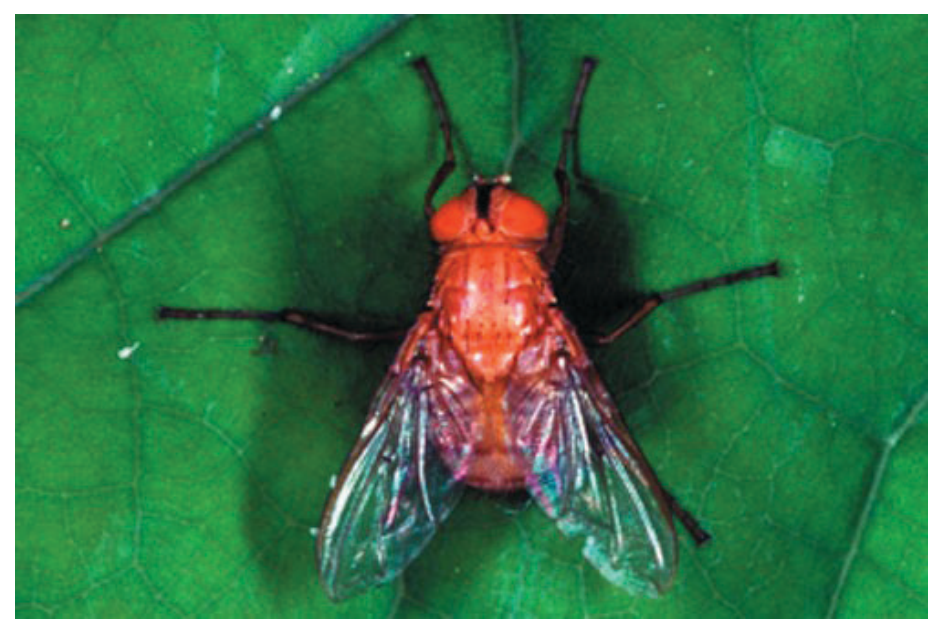

Figure 1. Ormia depleta (Wiedemann), the Brazilian red-eyed fly. Credits: Lyle J. Buss, UF/IFAS
Euphasiopteryx depleta (Wiedemann) is the only known synonym of Ormia depleta (Frank et al. 1996). The fly was listed as Euphasiopteryx depleta by Sabrosky (1953), but this name was later made a synonym of Ormia depleta by Wood (1987).

\section{Distribution}

Ormia depleta was first found in Brazil, in the 1930s (Frank and Walker 2006). According to Fowler and Kochalka (1985), it also has been recorded in Honduras and Peru. After being released in Florida in 1987, adults are thought to currently be present year-round in 28 counties, and seasonally present (fall) in an additional ten counties (Figure 2) (Frank and Walker 2006).

\section{Description}

Ormia depleta is a small tachinid fly, reaching 12 to $13 \mathrm{~mm}$ (0.5 inch) in size as an adult (UF/IFAS Extension 2018). Its body is a light tan/orange color, and it has bright red eyes, giving it the common name Brazilian red-eyed fly. The small larvae of this species are dark brown with creamcolored stripes (Figure 3). Ormia depleta pupae are dark in color, and much larger than the early-instars (Figure 4).

1. This document is EENY-708, one of a series of the Department of Entomology and Nematology, UF/IFAS Extension. Original publication date June 2018. Visit the EDIS website at http://edis.ifas.ufl.edu. This document is also available on the Featured Creatures website at http://entomology.ifas.ufl. edu/creatures.

2. Haleigh Ray; and Jennifer L. Gillett-Kaufman, associate Extension scientist, Department of Entomology and Nematology; UF/IFAS Extension, Gainesville, FL 32611 


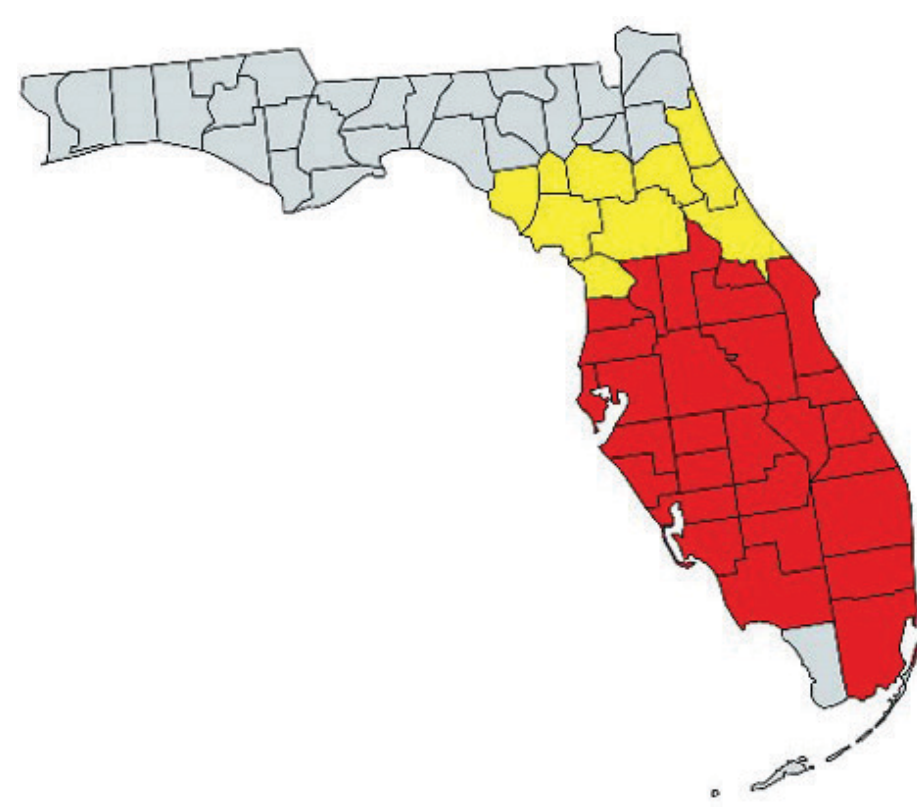

Figure 2. Counties in Florida where Ormia depleta (Wiedemann) can be found. Red counties indicate those where Ormia depleta is known to be present year-round, and yellow counties indicate the presence of Ormia depleta in the fall season.

Credits: Haleigh Ray using www.mapchart.net, following Frank et al. (1996).

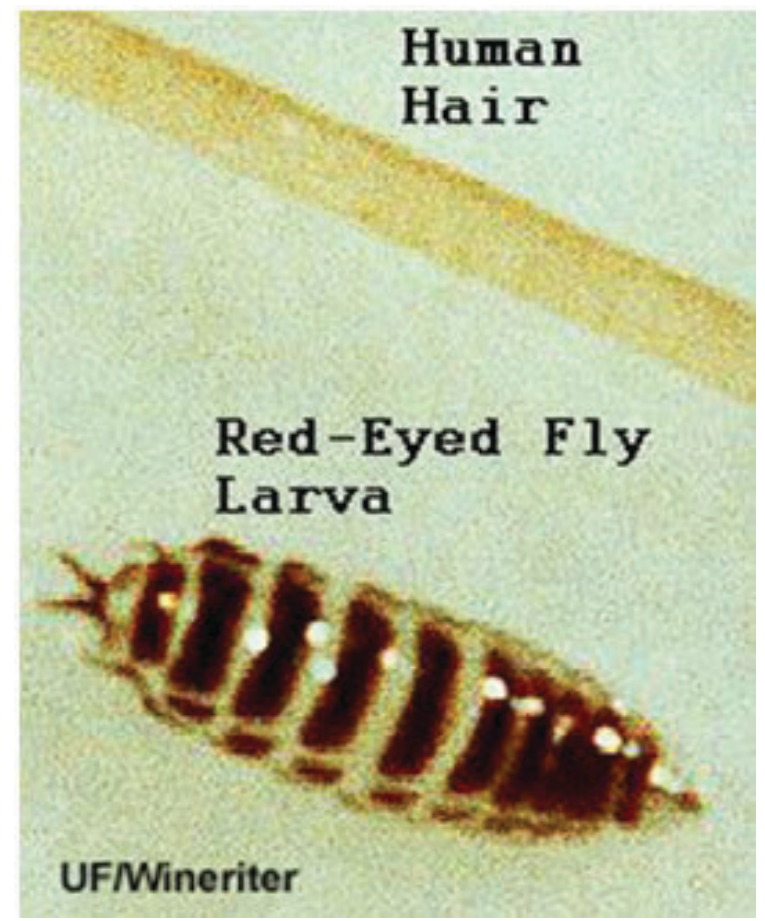

Figure 3. First instar larva of Ormia depleta next to a human hair for size comparison.

Credits: Susan Wineriter, University of Florida

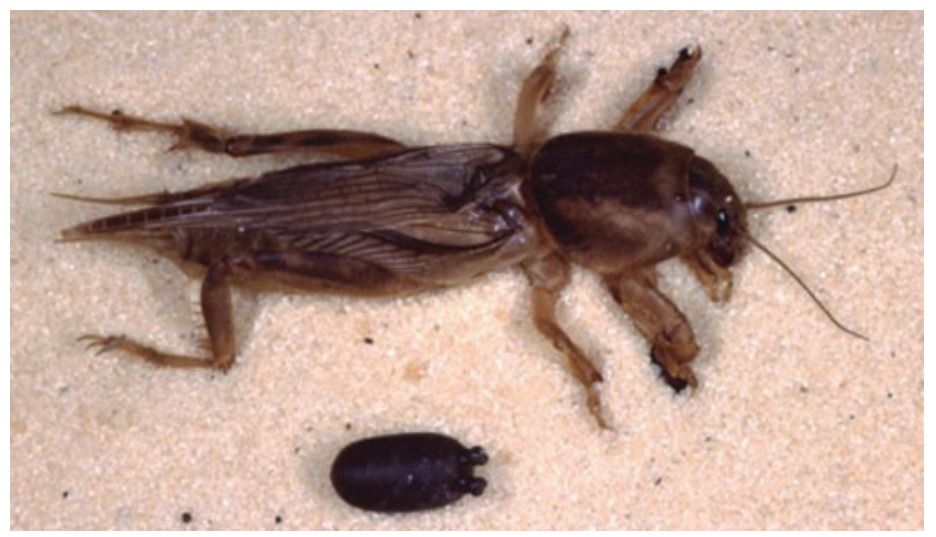

Figure 4. Pupa of Ormia depleta next to the mole cricket in which it developed.

Credits: Lyle J. Buss, UF/IFAS

\section{Life Cycle}

Gravid (pregnant) Ormia depleta females are attracted to the sounds produced by singing male mole crickets, which act as a host for these parasitoids. This has been demonstrated through use of audio units that replicate the song of a male mole cricket (Walker 1982, Fowler and Kochalka 1985). The eggs of Ormia depleta develop inside the female fly, and hatch before being placed onto a host.

After hatching, Ormia depleta females deposit their larvae onto mole crickets near the base of the wings, the area that produces the song (Frank and Walker 2006). From here, the larvae will tunnel into and parasitize the host. The larvae will eventually emerge out of the mole cricket body and burrow into the soil to pupate (Parkman and Frank 2002). After pupation, the adult fly emerges approximately 11 days later and, after mating, the cycle begins again. In a laboratory setting, the life cycle of Ormia depleta from egg to adult has been recorded to be about 36 days at $23^{\circ} \mathrm{C}-25^{\circ} \mathrm{C}$ (Wineriter and Walker 1990).

\section{Pest Management}

Ormia depleta was brought to the United States in an effort to reduce populations of pest mole crickets. It is a specialist parasitoid of species in the mole cricket genus Neoscapteriscus. Two mole cricket species that are pests in the southeast are Neoscapteriscus borellii (southern mole cricket) and Neoscapteriscus vicinus (tawny mole cricket), both of which are used as a host by Ormia depleta. However, another species of mole cricket in the southeast, Neocurtilla hexadactyla (northern mole cricket), is not used by the fly (Fowler 1987).

Pest mole crickets are a problem for turf and pasture grasses, and to better manage these pests, the University of Florida began a mole cricket research program in 1978 
(Frank et al. 1996). After being collected in Brazil and brought to the United States in 1983, a laboratory colony of Ormia depleta was successfully established at the University of Florida in 1987 (Frank et al. 1996). The following year, in 1988, it was first released in Florida (Frank et al. 1996). To find the best methods for rearing the flies, laboratory studies were conducted by Wineriter and Walker (1990). Researchers attempted to release Ormia depleta in Puerto Rico in the 1930s as well, but its establishment was unsuccessful (Frank and Walker 2006).

To implement biological control of mole crickets, University of Florida researchers reared Ormia depleta to the pupal stage, and a few days before adult emergence, placed boxes of pupae in 30 counties across Florida. Some of these releases were on golf courses, and others were areas chosen by Extension personnel (Frank et al. 1996). The flies were expected to be well established in some counties by 1991 . Because of the damage to golf courses, surveys were sent out in 1991 and 1992 to estimate the damage caused by the mole crickets. Results of this survey indicated that in counties where the fly was expected to be well established, $85 \%$ of the respondents reported less damage to the turf. Conversely, in the counties where the fly was not expected to be well established, there was only $46 \%$ less damage to the turf (Frank et al. 1996). Ormia depleta is estimated to be established in 28 counties in Florida and is successfully reducing pest damage from some Neoscapteriscus mole crickets (Frank and Walker 2006).

\section{Selected References}

Fowler HG. 1987. "Field behavior of Euphasiopteryx depleta (Diptera: Tachinidae): Phonotactically orienting parasitoids of mole crickets (Orthoptera: Gryllotalpidae: Scapteriscus)." Journal of the New York Entomological Society 95: 474-480.

Fowler HG, Kochalka JN. 1985. "New record of Euphasiopteryx depleta (Diptera: Tachinidae) from Paraguay: Attraction to broadcast calls of Scapteriscus acleus (Orthoptera: Gryllotalpidae)." Florida Entomologist 68: 225-226.

Frank JH, Walker TJ. 2006. "Permanent control of pest mole crickets (Orthoptera: Gryllotalpidae: Scapteriscus) in Florida." American Entomologist 52: 138-144.

Frank JH, Walker TJ, Parkman JP. 1996. “The introduction, establishment, and spread of Ormia depleta in Florida."

Biological Control 6: 368-377.
Parkman JP, Frank JH. 2002. "Interactions between Ormia depleta (Diptera: Tachinidae) and Steinernema scapterisci (Nematoda: Steinernematidae), natural enemies of pest mole crickets (Orthoptera: Gryllotalpidae)." Environmental Entomology 31: 1226-1230.

Sabrosky CW. 1953. "Taxonomy and host relations of the tribe Ormiini in the Western Hemisphere (Diptera: Larvaevoridae)." Proceedings of the Entomological Society of Washington 55: 167-305.

UF/IFAS Extension. (2018). Pest mole crickets and their control. Accessed 2 May 2018. http://entnemdept.ifas.ufl. edu/molecrickets/mcri0002.htm

Walker TJ. 1982. "Sound traps for sampling mole cricket flights (Orthoptera: Gryllotalpidae: Scapteriscus)." Florida Entomologist 65: 105-110.

Walker TJ, Parkman JP, Frank JH, Schuster DJ. 1996. "Seasonality of Ormia depleta and limits to its spread." Biological Control 6: 378-383.

Wineriter SA, Walker TJ. 1990. "Rearing phonotactic parasitoid flies (Diptera: Tachinidae, Ormiini, Ormia spp.)." Entomophaga 35: 621-632.

Wood DM. 1987. “Tachinidae.” Agriculture Canada Monograph 28: 1193-1269. 